\title{
INFLUÊNCIA DA ACESSIBILIDADE E EXTERNALIDADE NO MERCADO IMOBILIÁRIO DOS IMÓVEIS URBANOS SITUADOS "ALÉM LINHA" NO MUNICÍPIO DE PRESIDENTE PRUDENTE.
}

\author{
INFLUENCE OF ACCESSIBILITY AND EXTERNAL IN REAL ESTATE \\ MARKET OF URBAN PROPERTY LOCATED "BEYOND LINE" IN THE CITY \\ OF PRESIDENTE PRUDENTE.
}

Hudson Matheus Carvalho Santos, Mayara Cristina de Paula Felipe.

Universidade do Oeste Paulista - UNOESTE, Curso de Engenharia Civil, Presidente
Prudente, SP.
E-mail: hudcarvalho2@gmail.com

RESUMO - O município de Presidente Prudente teve sua expansão caracterizada pela implantação da estrada férrea Alta Sorocabana. Entretanto, esta expansão territorial assumiu um caráter altamente segregativo, ou seja, para as áreas com topografia mais íngremes destinaram-se as populações de baixo poder aquisitivo, por outro lado, as áreas mais planas foram ocupadas pelas classes que possuíam um poder aquisitivo maior. Diante disso a expansão territorial foi mais intensa a oeste da ferrovia, gerando assim as áreas além-linha (localizadas a leste da Estrada de Ferro Alta Sorocabana), isso se decorreu tanto pelo processo histórico dos baixos investimentos pela prefeitura nessas áreas, como também devido as barreiras psicológicas causadas pela estrada férrea. Nesse sentido, este estudo buscou identificar as influências de fatores como declividade, acessibilidade e infraestrutura no valor do metro quadrado construído da área alémlinha.

Palavras-chave: Estrada Férrea; Expansão Territorial; Segregação Socioespacial; Acessibilidade; Externalidades.

ABSTRACT - The municipality of Presidente Prudente had their expansion characterized by the implementation of the iron road High Sorocabana. However, this territorial expansion has taken on a highly segregated character, ie to, areas with steeper topography was earmarked populations with low purchasing power, on the other hand, the smooth plains were occupied by social classes who had a greater purchasing power. In this way, the territorial expansion was more intense west of the railroad, thus creating areas beyond the line

Recebido em: 19/08/2015 Revisado em: 10/09/2015 Aprovado em: 21/09/2015 (located east of the Railway High Sorocabana), that is held, by both the historical process of low investment by the municipality in these areas, as well as, because of the psychological barriers, caused by the iron road. In this sense, the study looked for identify the influences of 
factors such as: slope, accessibility and infrastructure in the value of the square meter of constructed area beyond the line.

Keywords: Rail Road; Territorial Expansion; Socio-Spatial Segregation; Accessibility; Externalities. 


\section{INTRODUÇÃO}

O Município de Presidente Prudente, localizado no extremo Oeste Paulista, teve sua expansão impulsionada pelo cultivo cafeeiro e caracterizada pela introdução da ferrovia Alta Sorocabana (Estrada de Ferro Sorocabana).

Nesse sentido Sposito (1983) ressalta que o povoamento mais expressivo da região foi consequência do desenvolvimento da economia cafeeira, sendo comandada pela expansão capitalista, assim a produção, a comercialização e as relações de trabalho passaram a serem organizadas pelo capital, estas mudanças provocaram transformações estruturais na área rural, estimulando o processo migratório do campo para a cidade, promovendo a urbanização.

A implantação da linha férrea propiciou o surgimento de um dualismo na cidade de Presidente Prudente, onde os bairros denominados além-linha sofreram de uma marginalização explicada por ser ocupada em sua grande maioria pela classe trabalhadora, assim, fora esquecida pela administração publica e lidara com a falta de recursos básicos para uma boa vivência.

Nesse sentido e diante do histórico local, houve, portanto, a necessidade de se desenvolver este trabalho para constatar a existência e influência desses fatores sob os setenta e quatro bairros que integram a área de estudo. Ressalta-se que este trabalho é parte do desdobramento das pesquisas realizadas para o desenvolvimento do Trabalho de Conclusão de Curso do Curso Técnico em Agrimensura da ETEC Prof. Dr. Antônio Eufrásio de Toledo.

\section{METODOLOGIA}

Utilizou-se no desenvolvimento desta pesquisa a revisão bibliográfica dos principais conceitos abordados seguida dos procedimentos referentes à avaliação de imóveis e análise das externalidades presentes no local.

$\mathrm{Na}$ avaliação dos imóveis o método empregado foi o comparativo, que consiste em obter o valor médio de um bem móvel ou imóvel a partir da comparação com outros do mesmo gênero ou semelhantes. Fiker (2008) afirma ser este método o mais recomendável para a avaliação de terrenos urbanos. Para obter os dados das transações utilizou-se anúncios de diversas imobiliárias de Presidente Prudente, estes foram coletados de novembro de 2013 a junho de 2014 .

Realizou-se ainda trabalhos de campo a fim de analisar as dinâmicas presentes nessas áreas, sobretudo as questões referentes ao padrão construtivo, infraestrutura existente, além de outros aspectos. 
AVALIAÇÃO DOS IMÓVEIS DA ZONA LESTE E NORTbteamentos da zona oeste e sul, sendo eles: DE PRESIDENTE PRUDENTE

Empregando o método comparativo e COHAB, Jardim Novo Bongiovani, Jardim Maracanã, Jardim Vale do Sol, Residencial posteriormente a operação matemática Maré Mansa, Parque Residencial média, obteve-se o valor médio do metro quadrado $\left(\mathrm{m}^{2}\right)$ construído por bairro (Figura Mediterrâneo e Residencial São Paulo, a fim de realizar uma análise comparativa.

01). Destaca-se que além dos bairros alémlinha foram coletados dados de alguns

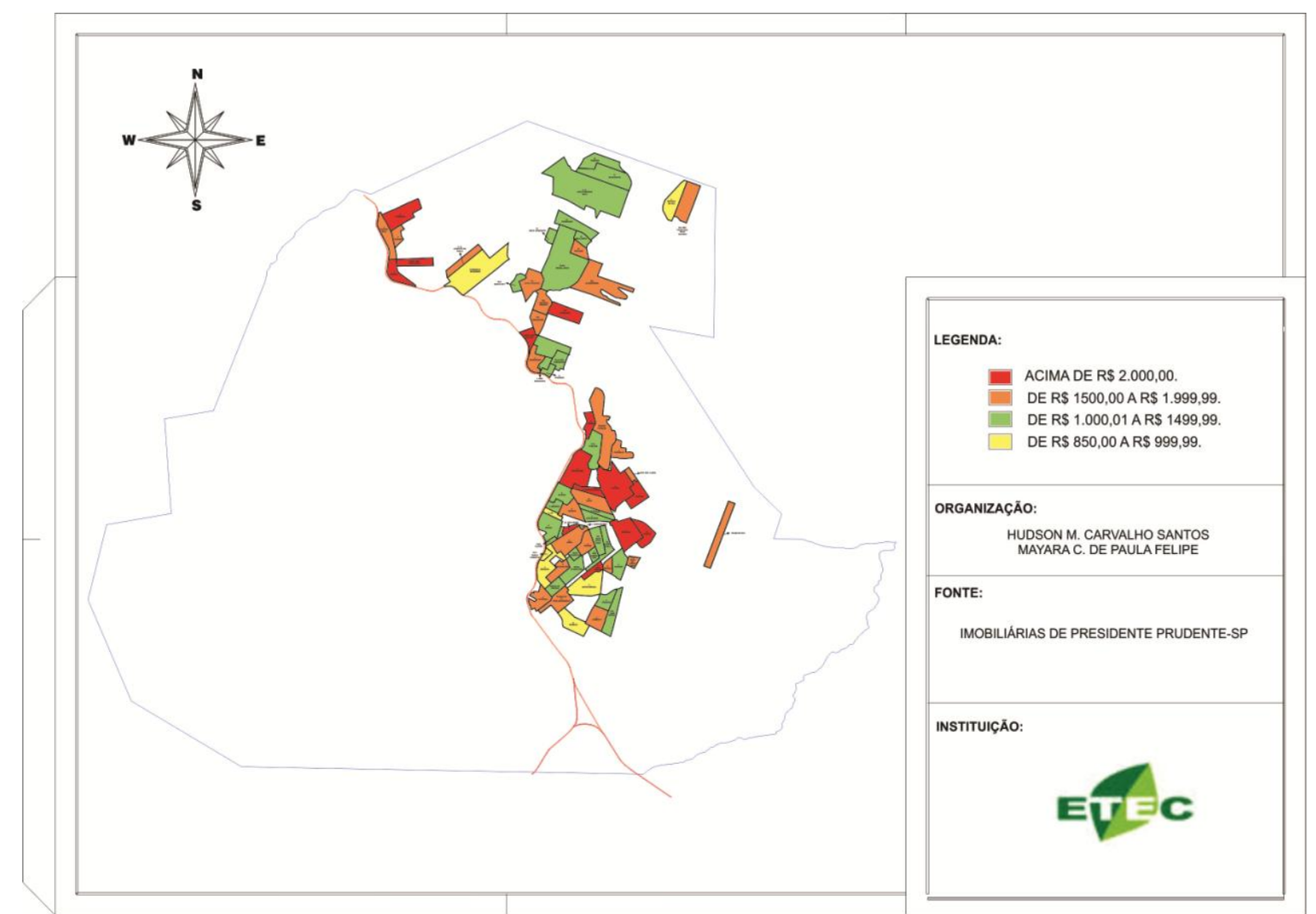

Figura 01: Média do $\mathrm{m}^{2}$ construído dos bairros além-linha de Presidente Prudente, 2014.

Objetivando a comparação entre as médias dos bairros além-linha com outros bairros da zona oeste e sul, obtivemos a média do metro quadrado construído de oito bairros (Tabela 01). 
Tabela 01. Média do $\mathrm{m}^{2}$ construído de bairros da Zona Oeste e Sul, 2014.

\begin{tabular}{c|c}
\hline BAIRROS & MÉDIA DO $\mathbf{M}^{2}$ CONSTRUÍDO \\
\hline Ana Jacinta & $\mathrm{R} \$ 2.903,13$ \\
\hline COHAB & $\mathrm{R} \$ 2.796,83$ \\
\hline Jd. Maracanã & $\mathrm{R} \$ 2.975,44$ \\
\hline Jd. Novo Bongiovani & $\mathrm{R} \$ 2.326,92$ \\
\hline Jd. Vale do Sol & $\mathrm{R} \$ 2.978,30$ \\
\hline Pq. Resid. Mediterrâneo & $\mathrm{R} \$ 2.874,85$ \\
\hline Resid. Maré Mansa & $\mathrm{R} \$ 3.064,57$ \\
\hline Resid. São Paulo & $\mathrm{R} \$ 2.832,47$ \\
\hline
\end{tabular}

Contudo, foi possível verificar que as médias dos bairros da zona oeste e sul são superiores a média dos bairros além-linha, mediante a essa comparação observou-se que as concepções históricas em relação à área além-linha influenciam na procura e consequentemente no valor dos imóveis presentes nessa porção.

No entanto, nos últimos anos essas áreas estão sendo mais requeridas pelo ramo da construção civil, essa procura decorre de tendências imobiliárias e de projetos de financiamentos lançados pelo governo Federal. Ainda nesse sentido, essas áreas são requeridas como uma alternativa altamente lucrativa, onde se compra um lote a um preço mais baixo que os situados na outra porção da cidade e edifica-se casas populares voltadas ao financiamento.

\section{DISCUSSÃO}

A segregação de Presidente Prudente, como já citado, se manifestou na expansão territorial da cidade. Em virtude disso observou-se que as áreas além-linha muitas vezes permaneceram pouco povoadas, por outro lado áreas mais distantes do centro urbanizaram-se.

Nesse cenário, aspectos como acessibilidade e externalidade influenciam na valorização ou desvalorização dos imóveis. Para Harvey (1980) apud Sposito (1983, p.9192), a acessibilidade diz respeito as facilidades e/ou dificuldades para ter acesso à determinadas atividades essenciais - como emprego, recursos, serviços de bem estar, entre outros. Já por externalidade, entendese o conjunto de implicações decorrentes "da alocação de atividade, serviços ou instituições, etc., que afetam a nossa localização, trazendo benefícios ou incômodos, sem que possamos decidir sobre isto, ou por eles estejamos pagando diretamente".

\section{ACESSIBILIDADE}

O fator acessibilidade, como já ressaltado, influência no preço de um imóvel urbano, pois é utilizado pelos agentes imobiliários como uma vantagem. Assim 
sendo, os locais mais valorizados do ponto de vista imobiliário são os que possuem uma maior acessibilidade, sendo alvo dos principais investimentos do mercado imobiliário.

No que tange a acessibilidade, o poder público tem um papel fundamental, uma vez que é a entidade responsável pela escolha das localizações onde serão implantados os meios de consumo coletivo. No entanto, esta esfera é constantemente pressionada pela iniciativa privada e por vezes toma decisões que privilegiam diretamente os cidadãos que possuem um elevado poder aquisitivo.

Em Presidente Prudente, a instalação nas décadas de 1970 e 1980, sobretudo, das camadas de menor poder aquisitivo em áreas em descontínuo à malha urbana, ocorreu sem a implantação de nenhuma melhoria.

Um fator que determina o nível de acessibilidade de um local é o acesso aos transportes coletivos. Nesse contexto, no ano de 2000 foi elaborado um estudo da Universidade Estadual Paulista, Faculdade de Ciências e Tecnologia, juntamente com a Prefeitura de Presidente Prudente, com o intuito de formar um sistema de informações para a tomada de decisão municipal (SPOSITO et al., 2000), onde constatou-se que a área "além-linha", zona leste e norte, apresentam uma acessibilidade, em geral, regular.
Ainda nesse contexto, Cruz (2012) salienta que a ausência de igualdade na distribuição do número de linhas de ônibus e a descontinuidade urbana, influenciam negativamente na acessibilidade dos habitantes dos bairros afastados e destaca que os principais problemas enfrentados pelos passageiros do transporte coletivo de Presidente Prudente são: má distribuição dos pontos de ônibus, inexistência de ponto de ônibus, longo tempo de espera entre um ônibus e outro, trajetos longos, lotação, má conservação dos ônibus, custo da passagem, dificuldades na integração, falta de informação, condução dos veículos e padrão de conforto.

No que se refere a acessibilidade, a disposição das vias é muito importante, pois é a partir delas que ocorrem a circulação das pessoas. Em Presidente Prudente, as principais vias ligam os diversos bairros ao centro. A zona leste possui um menor número de vias em virtude da sua topografia acidentada, apresentando um sistema viário desconexo dificultando a circulação.

Nos últimos anos o poder público tem investido nessas áreas através da implantação de equipamentos urbanos de destaque (FATEC, Centro Cultural Matarazzo, etc.) e equipamentos coletivos (Unidades de Sáude e Escolares), porém, Cruz (2012) ressalta que apesar dessa iniciativa não há 
nesta área equipamentos de destaque como existem nas demais localizações da cidade.

\section{EXTERNALIDADES}

A externalidade é uma variável fundamental na determinação do valor de um imóvel. Os bairros localizados além-linha apresentam em geral casas que variam entre baixo e médio padrão construtivo. Convém ressaltar, que os bairros próximos a área central, como Vila Marcondes, possuem muitas casas antigas de madeira.

Todavia, não é somente o padrão construtivo da casa que está relacionado a externalidade, mas também os aspectos físicos naturais e todo o conjunto de infraestrutura presente no bairro, neste ponto a prefeitura tem um papel importante, pois através das suas ações pode ocorrer a valorização ou até mesmo a desvalorização de uma área.

No entanto, o que se observou em Presidente Prudente relacionado área alémlinha é que existe um histórico de empreendimentos instalados nesse espaço que proporciona sua desvalorização, o mais destacado é a instalação de grande parte dos antigos locais de disposição de resíduos sólidos urbanos.

Em Presidente Prudente, das 25 áreas utilizadas para a deposição dos resíduos sólidos urbanos, entre 1923 e 2014, 18 localizam-se na área além-linha. As escolha dessas áreas seguiu principalmente o critério de "tapa buracos". Atualmente estão entregues ao descaso público (cobertas de mato em sua grande maioria), tornaram-se campinhos de futebol e praças mal planejadas que apresentam hoje problemas de rebaixamento ou subsidência que decorre da movimentação do terreno devido à decomposição das substâncias orgânicas presentes no lixo.

Em relação a topografia, o relevo da zona leste é marcado por declives acentuados o que dificultava a ocupação, como descreve Sudo e Leal (1996) apud Pedro (2011, p.158): O relevo se apresenta definido por um conjunto de espigões em colinas sedimentares convexizadas, de pequenas extensões. As vertentes são, predominantemente, convexo-retilíneas, terminando em vales encaixados relacionados a uma dentrificação mais acentuada da rede de drenagem. As vertentes mais inclinadas chegam a ter mais de $12 \%$ de declividade.

As áreas com declividade acentuada da zona leste foram ocupadas pela expansão da malha urbana, inicialmente nessas instalaram-se casas de baixo padrão construtivo, tanto em virtude da barreira psicológica que a linha férrea gerava como também em virtude da declividade. Assim sendo, muitos dos primeiros loteamentos dessa área eram ilegais. 


\section{CONCLUSÃO}

O processo de expansão territorial em Presidente Prudente e sua consequente segregação propiciaram as áreas situadas acima da linha férrea (zona leste e norte) grande deficiência, quando comparado ao restante da cidade, quanto a aspectos necessários a uma boa vivencia.

Nesse sentido, os imóveis situados na área estudada atualmente apresentam uma acessibilidade, em geral, regular, porem, não suficientes para atender a demanda. Quanto as externalidades esses bairros apresentam normalmente casas que variam entre baixo e médio padrão construtivo. Ademais, observou-se que nessa porção existe um histórico de empreendimentos instalados que proporciona sua desvalorização, o mais destacado é a instalação de grande parte dos antigos locais de disposição de resíduos sólidos urbanos. Ressaltando, que se trata de uma zona que possui uma declividade acentuada o que também influencia no valor do imóvel.

Mediante a comparação entre a área "além-linha" e a outra porção da cidade, quanto ao valor médio do metro quadrado e os fatores inerentes a essas áres (acessibilidade e externalidades), é possivel concluir que a acessibilidade e a problemáticas apresentadas quanto as externalidades são fatores de grande influencia na disparidade entre os valores médio do metro quadrado e, consequentemente, no mercado imobiliario.

\section{REFERÊNCIAS}

CRUZ, D. A. M. O. Transporte público coletivo em Presidente Prudente/SP: planejamento, mobilidade e acessibilidade no consumo do espaço urbano. 2012. 171f. Dissertação (Mestrado em Geografia) Faculdade de Ciências e Tecnologia da Universidade Estadual Paulista, Presidente Prudente - SP.

FIKER, J. Manual de avaliações e perícias em imóveis urbanos. 3. ed. São Paulo: Pini, 2008. $149 p$.

PEDRO, L. C. Geomorfologia urbana: impactos no ambiente urbano decorrente da forma de apropriação, ocupação do relevo. Geografia em Questão, v.04, n.01, p.153172, 2011.

SPOSITO, M. E. B. O chão em Presidente Prudente: a lógica da expansão territorial urbana. Dissertação de Mestrado em Geografia. Rio Claro: Instituto de Geociências e Ciências Exatas, Universidade Estadual Paulista, 1983. 230 p.

SPOSITO, E. S. et al. Sistema de informação para a tomada de decisão municipal. Relatório Final de Pesquisa - Fase 1. Presidente Prudente: CEMESPP - FCT/UNESP, 2000. 88f. 